\title{
年
}

\section{Palyatif Bakımda Tamamlayıcı ve Bütünleştirici Terapilerin Ağrı Yönetimine Etkisi: Bir Sistematik Derleme}

\author{
Duygu Yıldırım, Merve Kırşan, Servet Kıray, Esra Akın Korhan
}

İzmir Kâtip Çelebi Üniversitesi, Hemşirelik, İzmir, Türkiye

\section{Duygu Yıldırım}

Merve Kırşan

Servet Kıray

Esra Akın Korhan

\section{Iletişim:}

Merve Kırşan

İzmir Kâtip Çelebi Üniversitesi, Hemşirelik, İzmir, Türkiye

Tel: +905427125057

E-Posta: mervekirsan1167@gmail.com
ÖZET

Amaç: Bu çalışma, palyatif bakımdaki hastalara uygulanan tamamlayııı ve bütünleştirici terapilerin ağr yönetimine etkisi ile ilgili olan yayımlanmış çalışmaların gözden geçirilmesi ve çalışmadan elde edilen verilerin sistematik biçimde incelenmesi amacıyla gerçekleştirilmiştir.

Yöntem: Çalışma; Google Scholar, Pubmed, Science Direct, Proquest, Cochrane, EBSCOhost, Clinical Key, Ovid, Google Akademik veri tabanlarında, tarih aralığı 10 cak 2012-31 0cak 2017 ile sınırlandırilarak ve "reflexology, aromatherapy, music therapy, yoga, massage therapy, reiki, TENS, acupuncture, hypnosis, therapeutic touch, acupressure, mind and body practices, complementary and alternative medicine, pain management, palliative care", "refleksoloji, aromaterapi, müzik terapi, yoga, masaj terapi, transkütanöz elektiriksel sinir stimülasyonu, akupunktur, hipnoz, terapötik dokunma, akupresür, zihin-beden uygulamaları, tamamlayıcı ve alternatif terapi, ağrı yönetimi, palyatif bakım" anahtar kelimeleri ile ulaşılan ulusal ve uluslararası çalışmalar taranarak gerçekleştirilmiş̧tir. Araştırmaya dâhil edilme kriterlerine uyan 13 yayın çalışma kapsamında değerlendirilmişstir.

Bulgular: Araştırma kapsamına alınan çalışmalardan 4'ü tanımlayııı, 2'si restrospektif, 1'i kontrol grubu olmayan yarı deneysel mix method, 1'i yarı deneysel (randomize olmayan gruplarda ön test-son test kontrol gruplu), 2'si yarı deneysel (tek gruplu ön test- son test), 2'si deneysel (randomize kontrollï), 1'i nitel tasarıma sahiptir. Bu çalışmalarda "Vizüel Analog Skala (VAS)", "Measure Yourself Concerns and Wellbeing Questionnaire,", “Numerik Skala (NRS)", "Well-Being Scale”, "Fonksiyonel Ağrı Skalası," "Nursing Assessment of Pain Intensity Scale", "Yüz yüze Görüş̧me Tekniği", "The Edmonton Symptom Assessment Scale (ESAS)” veri toplama araçlarından yararlanılmıştır.

Sonuç: Konu ile ilgili çalışmaların sistematize edilmesi sonucu palyatif bakımdaki hastalara uygulanan tamamlayııı ve bütünleştirici terapiler ile hastaların algııladı̆ı ağrı şiddetinde azalma olduğuna dair kanıtlara ulaşıııı̧tır. Buradan hareketle, bu terapilerin palyatif bakımdaki hastaların ağrı yönetiminde kullanıı ldı̆ı ve kullanılabileceği sonuçlarına varıłımışıı.

Anahtar sözcükler: Palyatif bakım, tamamlayııı ve bütünleştirici terapiler, ağr yönetimi

THE EFFECT OF COMPLEMENTARY AND INTEGRATIVE THERAPIES ON PAIN MANAGEMENT IN PALLIATIVE CARE: A SYSTEMATIC REVIEW

ABSTRACT

Purpose: This study was conducted to investigate and systematically review the data obtained from published studies relating to the effect of complementary and integrative therapies on pain management of patients within palliative care units.

Method: This study was carried out using the Google Scholar, Pubmed, Science Direct, Proquest, Cochrane, EBSCOhost, Clinical Key, and Ovid databases. The search was limited to between 1 January 2012 and 31 January 2017 and retrieved both national and international research using the following keywords: reflexology, aromatherapy, music therapy, yoga, massage therapy, reiki, TENS, acupuncture, hypnosis, therapeutic touch, acupressure, mind and body practices, complementary and alternative medicine, pain management, palliative care. Thirteen publications were evaluated as being in accordance with the inclusion criteria for the content of the study.

Results: The publications comprised four descriptive studies, one retrospective study, one group with no controls, a quasi-experimental, mixed-methods design, one semi-experimental (pre-test and post-test control subgroups within non-randomized groups) design, two semi-experimental (single group pre-post-test, with randomized controls) and one qualitative design. The studies included made use of the "Visual Analogue Scale (VAS)", "Measure-Yourself Concerns and Wellbeing Questionnaire", "Numeric Scale (NRS)", "Well-Being Scale", "Functional Analog Scale (VAS)", "Pain Scale," "Nursing Assessment of Pain Intensity Scale,", "Face to Face Interview Technique" and "The Edmonton Symptom Assessment Scale (ESAS)". These data collection tools were used to evaluate the effect of complementary and integrative therapies on pain.

Conclusion: Evidence was collated through systematic review of all the relevant studies on complementary and integrative therapies applied to patients in palliative care settings and the decrease in the severity of pain perceived by the patients compared. On the basis of this review, it is concluded that these therapies can be used to manage pain in palliative care patients.

Keywords: Palliative care, complementary and integrative therapies, pain management
Gönderilme Tarihi : 13 Ekim 2017

Revizyon Tarihi : 170 cak 2018

Kabul Tarihi : 210 cak 2018 
P alyatif bakım; hastalar tarafından yaşanan fiziksel, psikolojik, sosyal ve manevi semptomların kapsamI olarak değerlendirilmesini, kontrolünü ve tedavi ile giderilmesini, yaşam kalitesinin arttırılmasını, acıların hafifletilmesini, ailenin ve/veya diğer bakım verenlerin desteklenmesini sağlayan bakımdır $(1,2)$. Palyatif bakım gereksinimi olan hasta grubunu; motor nöron hastalıkları, ilerleyici nöron hastalıkları, ileri dönem organ yetmezlikleri olan, HIV/AIDS veya tedavi sürecine yanıt vermeyen kanser tanısı olan, çocuklarda genetik/konjenital, ilerleyici hastalıkları olan hastalar oluşturmaktadır $(3,4)$. Palyatif bakım alan bu hastalar, yaşamı tehdit eden hastalıkla ilişkili olarak; ağrı, yorgunluk, bulantı, dispne, uykusuzluk, iştahsızlık, konstipasyon, üzüntü, endişe, anksiyete gibi birçok semptom deneyimleyebilmektedir. Bu semptomlar içinde en sık deneyimlenen, hastaların yaşam kalitesini en çok bozan, hasta ve ailesini en çok korkutan, gerçek ya da potansiyel doku hasarı ile ilişkili hoş olmayan duyusal ve duygusal deneyim olan ağrının yönetimi oldukça zordur (5-7). Palyatif bakım alan hastaların ağrı yönetiminde, farmakolojik ve non-farmakolojik yöntemler kullanılmaktadır. Farmakolojik yöntemler, hastalarda sedasyon, bulantı, konstipasyon, anemi gibi yan etkilere neden olabilmekte, hastaların ağrı eşiğini düşürebilmekte, aynı zamanda opioid analjeziklere bağımlılık oluşabilmektedir. Palyatif bakım hastalarında ağrı yönetimi sağlanırken aynı zamanda da bireylerin yaşam kalitesinin korunması gerekmektedir. Bu bağlamda analjezi etkisini oluşturma aynı zamanda hastaların yaşam kalitesini yükseltme adına palyatif bakımda ağrı yönetiminde non-farmakolojik yöntemler önem kazanmış ve gündeme gelmiştir. Sıcak uygulama, soğuk uygulama, deriye mentol uygulama, vibrasyon, TENS (Transkütan Elektiriksel Sinir Stimilasyonu), masaj terapi müzik terapi, aromaterapi, terapötik dokunma, akupunktur, akupressür, refleksoloji, reiki, hipnoz, gevşeme, dikkati başka yöne çekme, hayal kurma gibi zihin beden uygulamaları non-farmakolojik yöntemlerdir. Nonfarmakolojik yöntemler içinde yer alan tamamlayıcı ve bütünleştirici terapiler, deneyimlenen ağrı şiddetinin, ağrı yoğunluğunun azaltılması, hastaların ağrısının olmaması, analjezi tedavisi ile gelişebilecek yan etkilerin azaltılması ya da en aza indirilmesi ve hastanın ağrı yönetiminde aktif olarak yer alması adına önem arz etmektedir. Tamamlayıcı ve bütünleştirici terapiler, herhangi bir hastalık sürecinde var olan semptomların hafifletilmesi, tıbbi tedavinin etkinliğinin arttırılması ya da bireylerin yaşam kalitesinin yükseltilmesi, bireylere fiziksel ve emosyonel desteğin sağlanması için kullanılan sağlık bakım sistemleri, ürünleri ve uygulamalarıdır (8-12). Yaşamı tehdit eden hastalık kaynaklı problemlerle yüzleşen hastaların ve ailelerin yaşam kalitesini arttıran, hastaların ihtiyaçları üzerinde bütüncül ve multidisipliner bir yaklaşım sunan tamamlayıcı ve bütünleştirici terapiler, 1970'li yılların sonlarında kurulmuş olan palyatif bakım veren kurumlara entegre edilmeye başlamış ve bugün de birçok sağlık profesyoneli tarafından müzik terapi, masaj terapi, aromaterapi, akupunktur, akupressür, refleksoloji, reiki, terapötik dokunma gibi birçok tamamlayıcı ve bütünleştirici terapi yöntemi palyatif bakımda tercih edilen terapötik bir yaklaşım olmuştur (13-16). Literatür incelendiğinde; Nadjafi ve arkadaşlarının (2003) yapmış olduğu çalışmada palyatif bakım hastalarına uygulanan masaj terapi ile algılanan ağrı yoğunluğunun azaldığı ortaya konmuş (17), Bennet ve arkadaşlarının (2010) yapmış olduğu çalışmada palyatif bakım hastalarında TENS uygulamasının algılanan ağrı şiddetini azalttığı saptanmış (18), Mitchinson ve arkadaşlarının (2014) çaIışmasında ise palyatif bakımdaki hastaların ağrı yönetimi için masaj terapi uygulanmış ve hastaların ağrı yoğunluğunun azaldığı belirlenmiş (19), Ardigo ve arkadaşlarının (2016) yaptığı çalışmada ise hipnoz uygulanan hastalarda ağrı yoğunluğunun azaldığı ortaya konmuştur (20).

Tüm bu çalışma sonuçlarına dayanarak, palyatif bakım sürecinde yer alan hastaların ağrı yönetiminde tamamlayıcı ve bütünleştirici terapi yöntemlerinin kullanıldığı görülmektedir. Beşinci yaşamsal bulgu olarak kabul edilen ağrının yönetiminin etkin yapılması, palyatif bakım sürecinde yer alan hastaların fizyolojik ve psikososyal iyilik halinin devam ettirilmesi açısından önem arz etmektedir. Ağrı semptomunun yönetimi alışılagelmiş opioid/ non-opioid analjeziklerle yürütülmektedir. Özellikle yoğun bakım ünitelerinde ya da palyatif bakım sürecinde yer alan hastalarda uzun süreli opioid/non-opioid türevi analjeziklerin kullanımı bireylerde yarar-zarar dengesini negatif yöne çekmekte ve çeşitli komplikasyonlara neden olmaktadır. Bu bağlamda palyatif bakımda ağrı yönetiminde tamamlayıcı ve bütünleştirici terapilerin kullanımı oldukça önemlidir. Buradan hareketle palyatif bakımdaki hastalara uygulanan tamamlayıcı ve bütünleştirici terapilerin ağrı yönetimine etkisi ile ilgili olan yayımlanmış çalışmaların gözden geçirilmesi ve bu çalışmalardan elde edilen verilerin sistematik biçimde incelenmesi amacıyla planlanan bu sistematik derlemede şu sorulara cevap aranacaktır:

1. Tamamlayıcı ve bütünleştirici terapiler palyatif bakımda kullanılır mı?

2. Tamamlayıcı ve bütünleştirici terapilerin palyatif bakımda ağrı yönetimine etkisi var mıdır?

3. Palyatif bakımda tamamlayıcı ve bütünleştirici terapiler algılanan ağrı şiddetini azaltır mı? 


\section{Yöntem}

Bu sistematik derlemenin amacı, palyatif bakımda tamamlayıcı ve bütünleştirici terapilerin ağrı yönetimine etkisi ile ilgili yayımlanmış çalışmaların gözden geçirilmesi ve çalışmalardan elde edilen verilerin sistematik biçimde incelenmesidir. $\mathrm{Bu}$ amaç doğrultusunda üç araştırmacı tarafından "Google Scholar, Pubmed, Science Direct, Proquest, Cochrane, EBSCOhost, ClinicalKey, Ovid, Google Akademik" veri tabanları kullanılarak, "reflexology, aromatherapy, music therapy, yoga, massage therapy, reiki, TENS, acupuncture, hypnosis, therapeutic touch, acupressure, mind and body practices, complementary and alternative medicine, pain management, palliative care", "refleksoloji, aromaterapi, müzik terapi, yoga, masaj terapi, transkütanöz elektiriksel sinir stimülasyonu akupunktur, hipnoz, terapötik dokunma, akupresür, zihin-beden uygulamaları, tamamlayıcı ve bütünleştirici terapi, ağrı yönetimi, palyatif bakım" anahtar kelimeler ile ulaşılabilen, 1 Ocak 2012- 31 Ocak 2017 tarihlerinde yayımlanan orijinal araştırmalar çalışma kapsamına alınmıştır. Veri tabanlarındaki anahtar kelimeleri kapsayan araştırmaların başııkları ve özetleri dâhil edilme kriterleri yönünden ele alınmıştır. Tamamlayıcı ve bütünleştirici terapileri palyatif bakım ünitelerinde uygulayan çalışma olması, bu tamamlayıcı ve bütünleştirici terapilerin bakım alan hastaların ağrı düzeyinde etkisinin olması, aynı zamanda bu sistematik derlemeye alınan çalışmalarda tamamlayıcı ve bütünleştirici terapiler ile ağrı düzeyi arasındaki ilişkinin nicel veya nitel olarak ifade edilmesi ya da istatistiksel olarak test edilmesi sistematik derlemeye dâhil edilme kriterleridir. İngilizce ve Türkçe tam metin araştırmaların tümünü kapsayan bu sistematik derlemede, çalışmaların araştırma tasarımına ilişkin herhangi bir sınırlandırma getirilmemiş, tarama sonucunda 6914 veriye ulaşılmıştır. Başlığında ve/veya özetinde belirlenen anahtar kelimelerin herhangi birini veya birkaçını içeren 220 verinin özeti incelenmiş ve inceleme sonucunda 36 araştırmanın özetinde, palyatif bakım ünitelerinde uygulanan tamamlayıcı ve bütünleştirici terapilerin ağrı düzeyine etkisinin ele alındığı belirlenmiş, tam metnine ulaşılabilen 20 araştırma yukarıda belirtilen dâhil edilme kriterleri yönünden incelenmiş ve dâhil edilme kriterlerini taşıyan 13 araştırma sistematik derlemenin örneklemini oluşturmuştur (Şekil 1). Araştırmacılar arasındaki güvenirliği sağlamak için dördüncü bir araştırmacı tarafından tüm sayının \%10'u kadar olan 690 veri rastgele bir şekilde seçilip dâhil edilme kriterleri açısından incelenmiş ve değerlendirmeler arasında \%100'lük bir uyum olduğu tespit edilmiştir.

\section{Bulgular}

Sistematik derlemeye dâhil edilen araştırmaların 4'ü tanımlayıcı $(11,19,21,22), 2$ 'si restrospektif $(23,24)$, 1'i kontrol
Google Scholar, Pubmed, Science Direct, Proquest, Cochrane, EBSCOhost, Clinical Key, Ovid

"reflexology, aromatherapy, music therapy, yoga, massage therapy, reiki, TENS, acupuncture, hypnosis, therapeutic touch, acupressure, mind and body practices, complementary and alternative medicine, pain management, palliative care", "refleksoloji, aromaterapi, müzik terapi, yoga, masaj terapi, transkütanöz elektiriksel sinir stimülasyonu, akupunktur, hipnoz, terapötik dokunma, akupresür, zihin-beden uygulamaları, tamamlayıcı ve alternatif terapi, ağrı yönetimi, palyatif bakım"

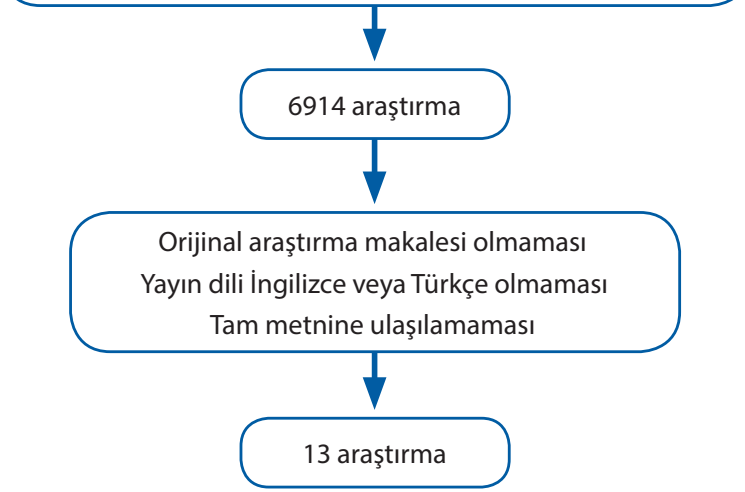

Şekil 1. Örneklemin belirlenme süreci

grubu olmayan yarı deneysel mix method (15), 1'i yarı deneysel (randomize olmayan gruplarda ön test-son test kontrol gruplu) (25), 2'si yarı deneysel (tek gruplu ön testson test) (16,26), 2'si deneysel (randomize kontrollü) $(5,28)$, 1'i nitel bir çalışmadır (27). Araştırma dâhilindeki çalışmaların 7'si Amerika Bileşik Devletleri'nde (5,11,19,22-24,26), 3'ü Almanya'da $(16,27,28)$ diğerleri ise Kanada'da (21), İngiltere'de (15) ve Hindistan'da (25) gerçekleştirilmiştir. Çalışmaların 5'i hastanelerde $(16,21,24,25,28)$, 4'ü sağlık merkezlerinde $(5,11,22)$, 2'si hospislerde $(26,27)$, 1 'i Ulusal Kalp, Akciğer ve Kan Enstitüsü'nde (23) ve 1'inde Amerika Birleşik Devletleri'nde kullanılan Sağlık Bakım Sistemi kayıtları ele alınarak yürütülmüştür (19). Çalışmaların örneklemi incelendiğinde, 11'inde yalnızca palyatif bakım hastaları, 2'sinde ise hasta ve hasta yakını çalışmaya dâhil edilmiştir. Araştırma kapsamına alınan çalışmaların hepsinde $(5,11,15,16,19,21-28)$ palyatif bakım ünitelerinde kullanılan tamamlayıcı ve bütünleştirici terapilerin ağrı düzeyi üzerindeki etkisi incelenmiştir.

Çalışmaların 12'sinde kullanılan tamamlayıcı ve bütünleştirici terapiler ile hastaların algıladıkları ağrının şiddetinde anlamlı düzeyde azalma olduğu (5,11,15,16,19,2127) saptanmıştır. Çalışmaların 1'inde ise kullanılan müzik terapinin algılanan ağrı şiddetine etki etmediği belirlenmiştir (28). 
Tablo 1. Araştırma kapsamına alınan çalışmaların özeti: palyatif bakımda tamamlayıcı ve bütünleştirici terapilerin ağı yönetimine etkisi

\begin{tabular}{|c|c|c|c|}
\hline \multirow[b]{2}{*}{ Yazar-YıI } & \multirow[b]{2}{*}{ Araştırma Tipi, Örneklem Grubu ve Sayısı } & \multicolumn{2}{|c|}{ Ölçüm Yöntemi } \\
\hline & & $\begin{array}{c}\text { Tamamlayıcı ve Bütünleştirici } \\
\text { Terapi Türü }\end{array}$ & Kullanılan Ölçekler \\
\hline $\begin{array}{l}\text { Selman ve } \\
\text { arkadaşları (2012) }\end{array}$ & $\begin{array}{l}\text { - Kalitatif tipte bir araştırmadır. } \\
\text { (Kontrol grubu olmayan, yarı deneysel, } \\
\text { mix method tasarımı) } \\
\text { Çalışma, Londra ve UK.'daki palyatif } \\
\text { bakım ünitesindeki } 18 \text { hasta ile } \\
\text { gerçekleştirilmiştir. }\end{array}$ & $\begin{array}{l}\text { - } \quad \text { Dans terapi } \\
\text { - } \quad \text { Yoga } \\
10 \text { hastaya yoga, } 5 \text { hasta dans terapi, } \\
3 \text { hastaya ise hem dans terapi hem de } \\
\text { yoga uygulanmıştır. } \\
\text { - } \quad \text { Yoga seansları 90dk, dans terapi } \\
\text { seansları ise } 60 \mathrm{dk} \text { sürmüştür ve bu } \\
\text { seanslar } 6 \text { hafta boyunca devam } \\
\text { etmiştir. }\end{array}$ & $\begin{array}{l}\text { Endişe ve İyilik Halini Ölçme Anketi } \\
\text { (Measure Yourself Concerns and } \\
\text { Wellbeing Questionnaie) }\end{array}$ \\
\hline Berger ve arkadaşları (2013) & $\begin{array}{l}\text { - } \quad \text { Tanımlayıcı tipte bir araşırımadır. } \\
\text { - } \quad \text { Çalışma Ontario hastanesinin palyatif } \\
\text { bakım ünitesindeki } 31 \text { hasta ile } \\
\text { yürütülmüştür. }\end{array}$ & $\begin{array}{ll}\text { - } & \text { Masaj Terapi } \\
\text { - } & \text { Aromaterapi } \\
\text { - } & \text { Reiki } \\
\text { - } & \text { Terapötik Dokunma } \\
\text { - } & \text { Hastalar bu terapilerden oluşan bir } \\
& \text { programa alınmıştır ve bu program } \\
& \text { birkaç ay sürmüşşur. }\end{array}$ & - Vizüel Analog Skala (VAS) \\
\hline $\begin{array}{l}\text { Gutgsell ve arkadaşları } \\
\text { (2013) }\end{array}$ & $\begin{array}{l}\text { - } \quad \text { Randomize kontrollü bir araştırmadır. } \\
\text { Çalışma Case Medical Center'a } \\
2009-2011 \text { yılları arasında yatan } \\
200 \text { hasta (100 deney, } 100 \text { kontrol) ile } \\
\text { yürütülmüştür. } \\
\text { - } \quad \text { Hastalar gruplara randomize atanmıştır. }\end{array}$ & 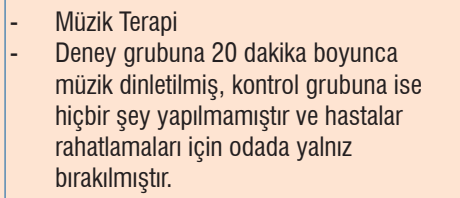 & $\begin{array}{ll}\text { - } & \text { Fonksiyonel Ağrı Skalası } \\
\text { - } & \text { Numerik Skala (NRS) } \\
\text { - } & \text { Yüz, Bacak, Aktivite, Ağlama Kontrol } \\
& \text { Edilebilirlik Ölçeği (The Face, Legs, } \\
& \text { Activity, Cry, Consolability Scale) }\end{array}$ \\
\hline Vandergrift (2013) & $\begin{array}{ll}\text { - } & \text { Tanımlayıcı tipte bir araştırmadır. } \\
\text { - } & \text { Çalış̧ma Connecticut Merkezi Hospis ve } \\
& \text { Palyatif bakım programındaki } \\
& 52 \text { hasta ile yürütülmüştür. }\end{array}$ & $\begin{array}{ll}- & \text { Reiki } \\
\text { - } & \text { Masaj Terapi } \\
\text { - } & \text { Hastaların tamamına toplam } 114 \\
& \text { seanslık reiki ve masaj terapi } \\
& \text { uygulanmıştır. }\end{array}$ & $\begin{array}{l}\text { - Masaj terapi ve reiki uygulamaları } \\
\text { sonrasında hastalar ile yüz yüze } \\
\text { görüşme tekniği }\end{array}$ \\
\hline Lu ve arkadaşları (2014) & $\begin{array}{ll}\text { - } & \text { Retrospektif tasarımına sahip bir } \\
\text { çalışmadır. } \\
\text { - } & \text { Çalışma Ulusal Kalp, Akciğer ve Kan } \\
\text { Enstitüsü'nün (NHLBI) Vasküler Hastalık } \\
\text { Bölümünde (NIH) 2005-2011 tarihleri } \\
\text { arasında palyatif bakım alan orak hücreli } \\
\text { anemi tanılı } 24 \text { hasta ile yürütülmüştür. }\end{array}$ & $\begin{array}{ll}\text { - } & \text { Akupunktur } \\
9 \text { hastaya yatarak, } 11 \text { hasta kronik ağrı } \\
\text { için ayaktan, } 4 \text { hasta da hem ayaktan } \\
\text { hem de yatarak akupunktur tedavisi } \\
\text { almıştır. } \\
\text { - } \\
\text { Hasta başına ortalama } 30 \text { dakikalık } 3 \\
\text { akupunktur seansı olmak üzere toplam } \\
\text { 48 seans gerçekleştirilmiştir. }\end{array}$ & - Numerik Skala (NRS) \\
\hline $\begin{array}{l}\text { Mitchinson ve arkadaşları } \\
\text { (2014) }\end{array}$ & $\begin{array}{l}\text { - } \quad \text { Tanımlayıcı tipte bir araştırmadır. } \\
\text { - } 2009-2010 \text { tarihleri Amerika Birleşik } \\
\text { Devletleri'nde, VA Ann Arbor Sağlık } \\
\text { Bakım Sistemine kayıtlı } 153 \text { palyatif } \\
\text { bakım hastası ile yürütülmüştür. }\end{array}$ & $\begin{array}{l}\text { - } \quad \text { Masaj Terapi } \\
\text { - Hastaların \% 52'si hastanede yatarak, \% } \\
\text { 37'si ayaktan, diğerleri ise hem ayaktan } \\
\text { hem de yatarak masaj terapi seanslarına } \\
\text { katılmıştır. }\end{array}$ & - $\quad$ İyilik Hali Skalası (Well-Being Scale) \\
\hline Teut ve arkadaşları (2014) & $\begin{array}{l}\text { - } \quad \text { Kalitatif pilot çalışmadır. } \\
\text { - } \quad \text { Çalışma Berlin Hospis'indeki } 8 \text { hasta ve } \\
3 \text { hasta yakını ile yürütülmüştür. }\end{array}$ & 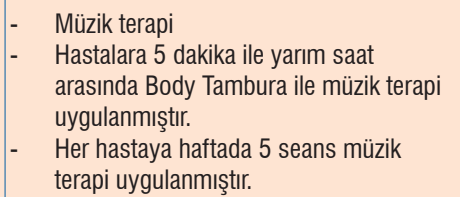 & $\begin{array}{l}\text { - Hasta ve hasta yakınları ile yüz yüze } \\
\text { görüşme tekniği }\end{array}$ \\
\hline Warth ve arkadaşları (2015) & 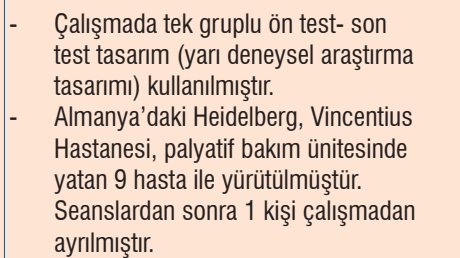 & $\begin{array}{ll}\text { - } & \text { Müzik terapi } \\
\text { - } & \text { Hastalara singing chair ile (müzik aleti) } \\
& 20 \text { dakika canlı müzik uygulanmışır. } \\
\text { - } & \text { Seanslar toplam 30-35 dakika devam } \\
\text { etmiştir ve hastalara sadece } 1 \text { seans } \\
\text { müzik terapisi uygulanmıştı. }\end{array}$ & - Vizüel Analog Skala (VAS) \\
\hline
\end{tabular}


Tablo 1 devamı. Araştırma kapsamına alınan çalışmaların özeti: palyatif bakımda tamamlayıcı ve bütünleştirici terapilerin ağıı yönetimine etkisi

\begin{tabular}{|c|c|c|c|}
\hline Romeo ve arkadaşları (2015) & $\begin{array}{l}\text { - } \quad \text { Ön test son test deneysel bir çalışmadır. } \\
\text { - } \quad \text { Çalışma 2011'de Amerika, All } \\
\text { Care Hospis'indeki } 26 \text { hasta ile } \\
\text { gerçekleştirmiştir. }\end{array}$ & $\begin{array}{ll}\text { - } & \text { Akupunktur } \\
\text { - } & \text { Hastalara süreleri } 20 \text { ila } 40 \text { dakika } \\
& \text { arasında değişen bireyselleştirilmiş bir } \\
& \text { akupunktur tedavisi uygulanmıştır. } \\
\text { - } & \text { Hastalar, haftada bir veya iki haftada } \\
\text { bir olmak üzere ortalama } 5 \text { akupunktur } \\
\text { tedavisi almıştır. }\end{array}$ & $\begin{array}{l}\text { Edmonton Semptom Değerlendirme } \\
\text { Ölçeği (The Edmonton Symptom } \\
\text { Assessment Scale -ESAS) }\end{array}$ \\
\hline $\begin{array}{l}\text { Krishnaswamy ve Nair } \\
\text { (2016) }\end{array}$ & $\begin{array}{ll}\text { - } & \text { Çalışmada randomize olmayan } \\
\text { gruplarda ön test-son test kontrol gruplu } \\
\text { karşıllaştırmalı tasarım (yarı deneysel } \\
\text { araştırma tasarımı) kullanıımıştır. } \\
\text { - } & \text { Hindistan St John's Tıp Fakültesi } \\
& \text { Hastanesi, Ağrı ve Palyatif Tıp Ünite'sine } \\
\text { ağrı yönetimi için başvuran } 14 \text { (7'si } \\
\text { kontrol, 7'si deney) kanser tanılı hasta ile } \\
\text { yürütülmüştür. }\end{array}$ & $\begin{array}{ll}\text { - } & \text { Müzik terapi } \\
\text { - } & \text { Deney grubuna } 20 \text { dakika boyunca } \\
& \text { kulakllk ile müzik dinletilmiştir; kontrol } \\
& \text { grubundaki hastalar ile de } 20 \text { dakika } \\
\text { - } & \text { boyunca sohbet edilmiştir. } \\
\text { Seanslar } 3 \text { hafta boyunca devam } \\
\text { etmiştir. }\end{array}$ & Numerik Skala [NRS] \\
\hline Warth ve arkadaşları (2016) & $\begin{array}{ll}\text { - } & \text { Randomize kontrollü çalışmadır. } \\
\text { - } & \text { Çalışma Heidelberg Vincentius Hastanesi } \\
& \text { Palyatif bakım ünitesinde yatan } 84 \text { hasta } \\
\text { (42kontrol, } 42 \text { deney) ile yürütülmüştür. } \\
\text { - } & \text { Hastalar deney ve kontrol gruplarına } \\
& \text { randomize olarak atanmıştır. }\end{array}$ & $\begin{array}{ll}\text { - } & \text { Müzik terapi } \\
\text { - } & \text { Deney grubuna monokord (müzik } \\
\text { aleti) ile } 20 \text { dakika boyunca canlı } \\
\text { müzik dinletilmiştir; kontrol grubundaki } \\
\text { hastalara ise kulaklık ile Dikkat Tabanlı } \\
\text { Stres Azaltma (MBSR) Programından } 20 \\
\text { dakikalık bir alıntı dinletilmiştir. }\end{array}$ & Vizüel Analog Skala (VAS) \\
\hline $\begin{array}{l}\text { Gallagher ve arkadaşları } \\
\text { (2017) }\end{array}$ & $\begin{array}{ll}\text { - } & \text { Retrospektif bir çalışmadır. } \\
\text { - } & \text { Çalışma 2000-2012 yılları arasındaki } \\
& \text { Cleveland Kliniği'nde yatarak tedavi } \\
\text { gören ve Palyatif Tıp danışmanlık hizmeti } \\
\text { alan } 293 \text { hasta ile yürütülmüştür. }\end{array}$ & $\begin{array}{ll}\text { - } & \text { Müzik terapi } \\
\text { - } & \text { Hastaların tercihlerine göre terapi } \\
& \text { seansları çeşitli şekilde (müzik dinleme, } \\
\text { sözlü/bilişsel katılım, şarkı sözü yazma, } \\
\text { sesli katılım, çalma, alkışlama, sözlü/ } \\
\text { duygusal katılım ve müzik yardımlı } \\
\text { gevşeme) yürütülmüştür. }\end{array}$ & $\begin{array}{l}\text { Numerik Skala (NRS) } \\
\text { Hemşire Ağrı Yoğunluğunu } \\
\text { Değerlendirme Skalası (Nursing } \\
\text { Assessment of Pain Intensity Scale) }\end{array}$ \\
\hline $\begin{array}{l}\text { Gallagher ve arkadaşları } \\
\text { (2017) }\end{array}$ & $\begin{array}{l}\text { - } \quad \text { Tanımlayıcı tipte bir araştırmadır. } \\
\text { - } \quad \text { Çalışma Harry Horvitz merkezi Palyatif } \\
\text { bakım ünitesindeki } 100 \text { hasta ve hasta } \\
\text { yakını ile yürütülmüştür. }\end{array}$ & $\begin{array}{ll}\text { - } & \text { Müzik Terapi } \\
\text { - } & \text { Oturumlar, hasta tercihli müziğin yanı } \\
\text { sıra müzik dinleme, şarkı söyleme, şarkı } \\
\text { seçme, enstrüman çalma, müzik destekli } \\
\text { gevşeme tekniklerine katılma, şarkı } \\
\text { sözlerini analiz etmeyi de içeren çeşitli } \\
\text { şekillerde yürütülmüştür. }\end{array}$ & $\begin{array}{ll}- & \text { Numerik Skala (NRS), } \\
\text { - } & \text { Hemşire Ağı Yoğunluğunu } \\
& \text { Değerlendirme Skalası (Nursing } \\
& \text { Assessment of Pain Intensity Scale) }\end{array}$ \\
\hline
\end{tabular}

\section{Tartışma}

$\mathrm{Bu}$ araştırmada, palyatif bakım ünitelerinde kullanılan tamamlayıcı ve bütünleştirici terapiler ile ağrı yönetimi arasındaki ilişkiye odaklanılmıştır. Çalışma kapsamına alınan araştırmaların büyük çoğunluğunda palyatif bakımda tamamlayıcı ve bütünleştirici terapilerin ağrı yönetimine olumlu yönde katkı sağladığı görülmüştür. Bu araştırmalardan biri olan Berger ve arkadaşlarının (2013) çalışmasında masaj terapinin, aromaterapinin, reikinin ve terapötik dokunmanın kullanılması ağrı yönetimine olumlu yönden etki ederek hastaların ağrılarını azalttığı saptanmıştır (21). Selman ve arkadaşları (2012) tarafından yürütülen kalitatif bir çalışmada palyatif bakım hastalarına uygulanan yoga ve dans terapinin ağrı yönetimine doğrudan etkisinin olduğu sonucuna varılmıştır (15). Lu ve arkadaşları (2014) tarafından gerçekleştirilen retrospektif bir çalışmada 2005-2011 tarihleri arasında palyatif bakım alan orak hücreli anemi tanısı olan hastalara belirli aralıklarla uygulanan akupunktur seansları sonucunda bu seansların hasta ağıı skorlarına pozitif yönden etki ettiği ve sayısal ağrı skalasında ortalama 2.1 puanlık bir düşüş olduğu tespit edilmiştir (23). Bir diğer araştırma olan, Krishnaswamy ve Nair (2016) tarafından yürütülen yarı deneysel çalışmada deney grubuna müzik terapi uygulanırken, kontrol grubu ile sohbet edilmiştir ve bunun sonucunda müzik terapisinden sonra deney grubundaki ağrı skorlarında istatistiksel olarak anlamlı azalma görülmüş olup kontrol grubunda ağrı skorunda azalma görülmemiştir. Ayrıca deney grubunda kontrol grubuna kıyasla müzik terapi sonrası ağrı skorlarında istatistiksel olarak anlamlı bir azalma olduğu tespit edilmiştir (25). Benzer şekilde Warth ve arkadaşları (2015) tarafından gerçekleştirilen çalışmada, müzik terapi uygulama öncesi ve sonrasında hastaların Vizüel Analog Skala skorları arasında minimal bir azalma olduğu gözlenmiştir ve bu azalmanın istatiksel olarak anlamlı olduğu sonucuna varılmıştır (16). Mitchinson ve arkadaşları (2014) tarafından 2009-2010 tarihleri arasında VA Ann Arbor Sağlık Bakım Sistemine kayıtlı 153 palyatif bakım hastası ile yürütülen 
bir çalışmada masaj terapi ile hastaların ağrı yoğunluğunda 1.65 oranında azalma gözlendiği ve kronik ağrısı olan hastaların ağrı yoğunluğunda kronik ağrısı olmayan hastalara kıyasla daha fazla azalma olduğu görülmüştür (19). Gutgsell ve arkadaşlarının (2013) palyatif bakım alan hastalarla yaptığı çalışma sonucunda müzik terapi uygulanan deney grubunun sayısal derecelendirme ölçeğindeki ağrı puanlarında ileri derecede anlamlı bir azalma görülmüştür ve ayrıca deney grubunun Fonksiyonel Ağrı Skalası puanları hiçbir uygulama yapılmayan kontrol grubunun puanlarından daha düşük bulunmuştur (5). Gallagher ve arkadaşlarının (2017) palyatif bakım danışmanlık hizmeti alan hastalarla yürüttüğü retrospektif bir çalışmada hastaların tercihlerine göre müzik terapi seansları çeşitli şekilde (müzik dinleme, sözlü/bilişsel katılım, şarkı sözü yazma, sesli katıım, çalma, alkışlama, sözlü/duygusal katılım ve müzik yardımlı gevşeme) gerçekleştirilmiştir ve bu seansların hasta ağrı skorlarına pozitif yönden etki ettiği, müzik terapisinden sonra hastaların ağrı düzeylerinde azalma olduğu saptanmıştır (24). Gallagher ve arkadaşlarının (2017) hasta ve hasta yakınları ile gerçekleştirdikleri bir diğer çalışmada hastaların ağrı puanlarında istatistiksel olarak anlamlı düzeyde azalma görülmüş ve hasta yakınları palyatif bakım ünitelerinde müzik terapisinin hastaları ve kendileri üzerinde olumlu bir etkiye sahip olduğunu bildirmiştir (22). Vandergrift (2013)'in çalışmasında hospis ve palyatif bakım programında yer alan reiki ve masaj terapi uygulanan hastalar ile uygulama sonrasında yüz yüze görüşülmüş ve görüşmeci tarafından hastaların \%76'sında masaj terapi ve reiki seanslarından sonra hastaların ağrılarının azaldığı bildirilmiştir ayrıca seanslardan sonra bir hastanın ifadesinin: "Sırtımın sol üstünde artık ağrı hissetmiyorum" şeklinde olduğu tespit edilmiştir (11). Warth ve arkadaşlarının (2016) çalışmalarında ise tersi bir sonuç elde etmiş olup, müzik terapisinden sonra hastaların ağrı algılamasında deney ve kontrol grupları arasında anlamlı bir fark bulunmamıştır ve müzik terapinin hastaların ağrı

\section{Kaynaklar}

1. World Health Organization 2017, WHO Definition of palliative care. Reviewed August 2017, http://www.who.int/mediacentre/ factsheets/fs402/en/.

2. Wiener L, Weaver MS, Bell CJ, Daly UM. Threading the cloak: palliative care education for care providers of adolescents and young adults with cancer. Clin Oncol Adolesc Young Adults 2012;5:1-18.

3. Borasio GD. Translating the World Health Organization definition of palliative care into scientific practice. Palliative \& Supportive Care 2011:9:1-2.

4. Kabalak AA, Öztürk H, Çağıl H. Yaşam Sonu Bakım Organizasyonu; Palyatif Bakım. Yoğun Bakım Dergisi 2013;11:56-70. düzeylerine etki etmediği saptanmıştır (28). Teut ve arkadaşlarının (2014) 8 hasta ve 3 hasta yakını ile yürüttükleri pilot çalışmada uygulanan müzik terapi sonrasında bir aile üyesi, hastasının tedaviden sonra ağrısında azalma olduğunu bildirmiştir (27). Romeo ve arkadaşlarının (2015) çalışmasında hastalara süreleri 20 ile 40 dakika arasında değişen bireyselleştirilmiş bir akupunktur tedavisi sonrasında hastaların ağrı düzeylerine bakıldığında hastaların ağrı şiddetinde anlamlı düzeyde azalma olduğu saptanmıştır (26).

Bu sistematik derleme ile tamamlayıcı ve bütünleştirici terapilerden "yoga, dans terapi, akupunktur, müzik terapi, masaj terapi, reiki, aromaterapi, terapötik dokunma"nın kullanılmasının palyatif bakımdaki hastaların ağrı yönetimi üzerinde olumlu yönde etki gösterdiği saptanmıştır.

\section{Sonuç}

Bu sistematik derleme ile palyatif bakımda uygulanan tamamlayıcı ve bütünleştirici terapilerin ağrı yönetiminde kullanıldığı görülmektedir ve bu terapilerin ağrı yönetimine pozitif yada negatif yönde etki ettiği doğrulanmıştır. Sistematik derlemeden elde edilen bulgular çerçevesinde tamamlayıcı ve bütünleştirici terapilerden "yoga, dans terapi, akupunktur, müzik terapi, masaj terapi, reiki, aromaterapi, terapötik dokunma"nın hastaların algıladığı ağrı şiddetinde anlamlı bir azalma sağladığı sonucuna ulaşımıştır. Tamamlayıcı ve bütünleştirici terapilerin, palyatif bakım hastaları da dâhil olmak üzere ağrı deneyimleyen bütün hastalara uygulanması hastaların ağrı yönetiminde pozitif yönde katkı sağlayabilir. Bu bağlamda, tamamlayıcı ve bütünleştirici terapilerin ağrı yönetimi üzerindeki etkisini belirleyebilecek geniş örneklem çalışmalarının yapılması ve etkili terapilerin belirlenip, bu terapilerin klinik ortamlarda test edilmesi ve de kliniklerde kullanımının gerçekleştirilmesi önerilmektedir.

5. Gutgsell KJ, Schluchter M, Margevicius S, et al. Music therapy reduces pain in palliative care patients: a randomized controlled trial. Journal of Pain and Symptom Management 2013;45:822-31.

6. Stewart M, Cox-Davenport RA. Comparative Analysis of Registered Nurses' and Nursing Students' Attitudes and Use of Nonpharmacologic Methods of Pain Management. Pain Management Nursing 2015;16:499-502.

7. Uysal N, Şenel G, Karaca Ş, Kadıoğulları N, Koçak N, Oğuz G. Palyatif Bakım Kliniğinde Yatan Hastalarda Görülen Semptomlar ve Palyatif Bakımın Semptom Kontrolüne Etkisi. Ağrı 2015;27:104-10.

8. Özçelik H, Fadıloğlu Ç. Kanser hastalarının tamamlayıcı ve alternatif tedavi kullanım nedenleri. Türk Onkoloji Dergisi 2009;24:48-52. 
9. Özveren H. Ağrı Kontrolünde Farmakolojik Olmayan Yöntemler. Hacettepe Üniversitesi Sağlık Bilimleri Fakültesi Hemşirelik Dergisi 2011:83-92.

10. Egan B, Gage H, Hood J, et al. Availability of complementary and alternative medicine for people with cancer in the British National Health Service: Results of a national survey. Complementary Therapies in Clinical Practice 2012;18:75-80.

11. Vandergrift A, Use of Complementary Therapies in Hospice and Palliative Care*. Omega 2013;67:227-32.

12. Hökkä $M$, Kaakinen $P$, Pölkki T. A systematic review: nonpharmacological interventions in treating pain in patients with advanced cancer. Journal of advanced nursing 2014;70:1954-69.

13. Dhalla S, Chan KJ, Montaner JS, Hogg RS. Complementary and alternative medicine use in British Columbia-a survey of HIV positive people on antiretroviral therapy. Complementary Therapies in Clinical Practice 2006;12:242-8.

14. Mao JJ, Farrar JT, Xie SX, Bowman MA, Armstrong K. Use of complementary and alternative medicine and prayer among a national sample of cancer survivors compared to other populations without cancer. Complementary therapies in medicine, 2007;15:21-9.

15. Selman LE, Williams J, Simms V. A mixed-methods evaluation of complementary therapy services in palliative care: yoga and dance therapy. European journal of cancer care 2012;21:87-97.

16. Warth M, Kessler J, Kotz S, Hillecke TK, Bardenheuer HJ. Effects of vibroacoustic stimulation in music therapy for palliative care patients: a feasibility study. BMC complementary and alternative medicine 2015;15:1-8.

17. Nadjafi T, Rahimiha F, Mohaddes Ardebili F, Hosseini F. Effect of Foot Massage on Relaxation and Pain Intensity of Cancer Patients. Iran J Nurs 2003;15:75-82.

18. Bennett MI, Johnson MI, Brown SR, Radford H, Brown JM, Searle RD. Feasibility study of Transcutaneous Electrical Nerve Stimulation (TENS) for cancer bone pain. The Journal of Pain 2010;11:351-9.
19. Mitchinson A, Fletcher CE, Kim HM, Montagnini M, Hinshaw DB. Integrating massage therapy within the palliative care of veterans with advanced illnesses: an outcome study. American Journal of Hospice and Palliative Medicine 2014;31:6-12.

20. Ardigo $\mathrm{S}$, Herrmann FR, Moret $\mathrm{V}$, et al. Hypnosis can reduce pain in hospitalized older patients: a randomized controlled study. BMC Geriatrics 2016;16:1-8.

21. Berger L, Tavares M, Berger BA. Canadian experience of integrating complementary therapy in a hospital palliative care unit. Journal of palliative medicine 2013;16: 1294-8.

22. Gallagher LM, Lagman R, Bates D, et al. Perceptions of family members of palliative medicine and hospice patients who experienced music therapy. Supportive Care Cancer 2017;25:1769-78.

23. Lu K, Cheng MJ, Ge X, et al. A retrospective review of acupuncture use for the treatment of pain in sickle cell disease patients: descriptive analysis from a single institution. The Clinical journal of pain 2014;30:825-30.

24. Gallagher LM, Lagman R, Rybicki L. Outcomes of music therapy interventions on symptom management in palliative medicine patients. American Journal of Hospice and Palliative Medicine 2017;1-8

25. Krishnaswamy $P$, Nair S. Effect of music therapy on pain and anxiety levels of cancer patients: A pilot study. Indian journal of palliative care 2016;22:307-11

26. Romeo MJ, Parton B, Russo RA, Hays LS, Conboy L. Acupuncture to treat the symptoms of patients in a palliative care setting. Explore: The Journal of Science and Healing 2015;11:357-62.

27. Teut M, Dietrich C, Deutz B, Mittring N, Witt CM. Perceived outcomes of music therapy with Body Tambura in end of life care-a qualitative pilot study. BMC palliative care,2014;13:1-8.

28. Warth M, Kessler J, Hillecke TK, Bardenheuer HJ. Trajectories of Terminally III Patients' Cardiovascular Response to Receptive Music Therapy in Palliative Care. Journal of pain and symptom management 2016;52:196-204. 